\title{
A formação de alianças estratégicas: uma análise teórica a par- tir da teoria da dependência de recursos e da teoria dos custos de transação
}

\section{The formation of strategic alliances : a theoretical analysis from the theories of resource dependency and transaction costs}

\author{
Leonardo Querido Cárdenas ${ }^{1}$ \\ Fernando Dias Lopes ${ }^{2}$
}

\begin{abstract}
Resumo
A formação de alianças estratégicas é uma tendência cada vez mais evidente no atual ambiente organizacional, sendo uma das principais estratégias utilizadas pelas organizações para manterem-se competitivas. Nesse sentido, este artigo apresenta o que são alianças estratégicas e quais os motivos que levam as organizações contemporâneas a formarem esse tipo de arranjo cooperativo, demonstrando suas principais características e as vantagens competitivas que pode trazer o seu estabelecimento. Em seguida, é feita uma análise sobre como a tendência de formação de alianças estratégicas pode ser entendida segundo duas diferentes abordagens teóricas: a teoria da dependência de recursos e a teoria dos custos de transação. Assim, procurar-se-á inicialmente estabelecer uma contextualização a respeito de como e porque se dá a formação dessas alianças, buscando-se em seguida entender as abordagens teóricas explicitadas para, então, verificar de que forma estas procuram interpretar esse fenômeno organizacional. Por fim, procura-se correlacionar de que forma essas abordagens se cruzam, numa tentativa de esclarecer os motivos da formação de arranjos cooperativos.

Palavras-chave: alianças estratégicas; teoria da dependência de recursos; teoria dos custos de transação.

Abstract

The formation of strategic alliances is clearly evident on the current organizational setting. It's one of the main strategies used by organizations that want to remain competitive. In this sense, this article aims to explain what are strategic alliances and what are the reasons why contemporary organizations form this kind of cooperative set, demonstrating its main characteristics and the advantages that can be achieved by establishing such alliances. Afterwards, an analysis on how the tendency of formation of strategic alliances can be understood is done according to two different theoretical approaches: the theory of resource dependency and the transaction costs theory. Therefore, it is intended to contextualize how and why these alliances are formed, trying to understand these theoretical approaches with the objective of verifying how they interpret this organizational phenomenon. Finally, this study tries to correlate how these approaches match in an attempt to clarify the reasons of forming cooperative sets.
\end{abstract}

Keywords: strategic alliances; resource dependency theory; transaction costs theory.

${ }^{1}$ Mestrando em Administração pela Universidade Federal do Rio Grande do Norte-UFRN. Endereço : Av. Campos Sales, 767, Apto. 701 Natal/RN - Brasil - CEP: 59020300. E-Mail: leonardoquerido@hotmail.com

${ }^{2}$ Doutor em Administração pela Universidade Federal do Rio Grande do Sul-UFRGS. Endereço : Rua Visconde de Abaete, 2804, Capim Macio, Natal, RN, Brasil CEP: 59082480. E-Mail : flopes@ufrnet.br

Artigo recebido em dezembro de 2005 e aceito para publicação em março de 2006. 


\section{Introdução}

As organizações da era capitalista sempre se caracterizaram por seu dinamismo e sua capacidade de adaptação às circunstâncias, características de fundamental importância para a própria sobrevivência das organizações em mercados cada vez mais competitivos. Nesse sentido, diversas transformações e inovações têm ocorrido com freqüência cada vez maior, sendo importante frisar que organizações com pouca flexibilidade para adaptações a novos ambientes dificilmente conseguem manter-se por longo tempo numa economia cada vez mais competitiva e globalizada.

Nas últimas décadas, a tendência de surgimento de alianças visando a uma cooperação entre organizações capitalistas parece demonstrar a adaptação de muitas empresas a esse novo contexto. Esse novo tipo de arranjo vem se tornando uma característica cada vez mais predominante no ambiente organizacional, indicando uma possível reação de muitas empresas a uma nova conjuntura caracterizada por grande dinamismo e rápidas transformações tecnológicas, onde se torna fundamental para algumas empresas associarem-se a outras para que possam obter conhecimento e manterem-se a par das novas tecnologias, o que é essencial para que permaneçam competitivas. Ademais, esse novo contexto de grandes avanços nas telecomunicações, de diminuição nos custos e no tempo de transporte, de formação de blocos econômicos regionais e de globalização tem criado um ambiente cada vez mais propício a essas alianças. Das e Teng (2000) afirmam que a proliferação de alianças estratégicas nos últimos anos marcou uma mudança no conceito do que seja natureza da competição, caracterizada cada vez mais por constantes inovações tecnológicas e rápidas inserções em novos mercados. Tais fatores, dentre outros, têm levado à noção de que a chave para o sucesso está em conseguir vantagem colaborativa através da formação de alianças.

Esse novo ambiente organizacional tem possibilitado a criação de arranjos cooperativos que garantem benefícios efetivos às organizações que estejam dispostas a cooperarem entre si. São benefícios que vão de uma significativa redução dos custos de transação até a conquista de melhor posicionamento no mercado por uma ou mesmo a oportunidade de se adquirir determinados conhecimentos organizacionais. Contractor e Lorange (1988) explicitam sete benefícios trazidos pela formação de uma aliança estratégica:

- redução de riscos, pois a cooperação permite que as empresas dividam os riscos do negócio;

- economia de escala, pela maior eficiência conseguida com o uso mais efetivo dos ativos de uma empresa, o que reduz custos;

- intercâmbio tecnológico com a troca de conhecimento entre as empresas que, assim, conseguem aperfeiçoar sua tecnologia;

- menor concorrência pela conquista de uma determinada posição no mercado, a partir do momento em que as empresas que firmaram a aliança deixam de ser concorrentes e passam a cooperar;

- atuação dentro de fronteiras, a partir da eliminação de barreiras legais, quando se estabelece aliança com uma empresa local;

- facilitação do ingresso de empresas pouco experientes no mercado internacional, pois uma aliança permite a uma empresa adquirir os conhecimentos necessários para atuar em diferentes mercados de forma eficiente; e

- os autores explicitam a vantagem de se estabelecer uma integração quase-vertical por intermédio de uma aliança.

No entanto, é preciso ter em vista que a cooperação através da formação de alianças não traz apenas benefícios para as organizações - e nem sempre deve ser encarada como a melhor estratégia -, devendo-se analisar cada caso cuidadosamente. 
Rodrigues (1999) coloca a possibilidade de surgirem conflitos numa aliança, que podem ameaçar a sua existência. Um dos fatores apontados como causadores de conflitos seria a formulação de acordos-base, que deveriam ser exaustivamente discutidos antes de serem firmados, mas que, uma vez assinados, devem ser postos de lado e jamais consultados no caso de algum impasse, pois isso levaria a uma grave discordância entre os parceiros. Outro fator de conflito seria o eventual desinteresse de um dos parceiros, seja por fatores conjunturais ou mesmo por ele já ter atingido os objetivos que o motivaram a formar a aliança. Um terceiro fator seria as diferenças culturais entre profissionais envolvidos em, por exemplo, uma joint venture, haja vista que culturas muito distintas poderiam inviabilizar a continuidade de uma cooperação, em virtude do choque cultural e de diferenças de pontos de vista.

Vários outros fatores de risco também devem ser levados em conta na formação de uma aliança, como a possibilidade de comportamento oportunista e o risco de se investir com um parceiro de pouca credibilidade. É importante ter em mente que arranjos cooperativos podem abrir excelentes possibilidades estratégicas; mas, antes de efetivar sua formação, deve-se verificar até que ponto as vantagens de se estabelecer tal arranjo superam as desvantagens. Cabe frisar que, apesar dos riscos e das desvantagens inerentes à formação de uma aliança, esta parece ser uma estratégia de fundamental importância para as organizações contemporâneas:

Ainda que o índice de fracassos seja alto, o número de alianças sendo formadas está crescendo em virtude do seu grande potencial de criação de valor. Resultados recentes mostram que mais de $80 \%$ dos executivos pesquisados vêem a formação de alianças estratégicas como um veículo essencial para o crescimento e acreditam que essas alianças irão responder por $25 \%$ do valor de mercado de suas companhias em 2005. (SCHIFRIN, 2001 apud IRELAND; HITT, VAIDYANATH, 2002, p.439)

Nesse sentido, este artigo visa fazer uma breve análise sobre como a tendência de formação de alianças estratégicas verificada nas últimas décadas pode ser explicada através da perspectiva de duas abordagens teóricas contemporâneas: a teoria da dependência de recursos e a teoria dos custos de transação.

\section{A formação de alianças estratégicas vista da perspectiva da teoria da dependência de recursos}

A teoria da dependência de recursos é um modelo baseado em grande parte nas discussões de Pfeffer e Salancik (1978). Esse modelo parte do pressuposto de que as decisões são tomadas no interior das organizações, e de que essas decisões devem sempre levar em consideração o ambiente no qual estão inseridas. Porém, diferentemente da perspectiva de análises anteriores, de passividade em relação a esse ambiente, essa abordagem teórica parte do pressuposto de que as organizações podem influenciá-lo de forma ativa, tentando formatá-lo da forma mais conveniente possível, tendo o dirigente, nesse sentido, papel preponderante.

Segundo essa abordagem, a organização é dependente de uma série de recursos, sem os quais se torna impossível sua sobrevivência. Esses recursos podem ser financeiros, físicos, humanos ou organizacionais (BARNEY, 1991 apud BARNEY; HESTERELY, 2004). Contudo, nenhuma organização tem a capacidade de ser autosuficiente em relação aos recursos de que necessita, sendo, portanto, esse modelo considerado interorganizacional. Nesse sentido, toda organização deve procurar uma estratégia que busque esses recursos da forma mais eficiente possível (HALL, 2004), já que, como dito anteriormente, grande parte dos recursos mais valiosos são raros e muito difíceis de serem imitados ou substituídos. Dessa forma, quando uma determinada firma necessita de um fator de produção, tem três possibilidades de conseguir obtê-lo: produzindo-o por conta própria, buscando-o no mercado ou conseguindo-o através de alianças com parceiros que possuam esses recursos (DAS e TENG, 2000). O terceiro caso, como se tem observado nas últimas décadas, parece ser uma tendência cada vez mais comum.

A formação de alianças cooperativas tem se mostrado uma estratégia eficiente de forma a facilitar o acesso das organizações a muitos recursos dos quais elas dependem. De forma geral, as organizações recorrem a essas formas colaborativas para obter os recursos que outras firmas dispõem e que são essenciais para atingirem um determinado nível de vantagem competitiva. Além disso, visam a possibilidade de desenvolverem novos recur- 
sos que não poderiam ser gerados independentemente, conforme afirmam Ireland, Hitt e Vaidyanath (2002, p.428): "Um dos principais benefícios das alianças é o acesso a recursos previamente não disponíveis e o desenvolvimento em conjunto de novos recursos". Desse modo, ao explicar a formação dessas alianças, a teoria da dependência de recursos sugere que as firmas utilizam essas formas de cooperação para alcançar um ótimo nível de alocação dos recursos, no qual o valor destes procura ser maximizado em relação a possíveis outras combinações (DAS E TENG, 2000). No entanto, é importante deixar claro que embora este seja um argumento oriundo da resource based-view, ele vai ao encontro das proposições da teoria da dependência de recursos, pois ao apontar a possibilidade de desenvolvimento de determinados recursos internos diferenciados, a organização estaria reduzindo sua dependência em relação a outros atores no ambiente organizacional.

A busca por recursos parece ser, portanto, um fator preponderante na formação de alianças entre empresas, sendo para alguns autores, o principal motivo para tal. Por exemplo, Glaister e Buckley (1996) afirmam que a busca de acesso a determinados recursos é o principal motivo para que firmas se aliem, superando outras motivações, como a divisão de riscos ou mesmo o ganho de economia de escala. Contudo, é importante ter em vista que alianças podem visar à obtenção de diferentes tipos de recursos, tangíveis ou não. Esses recursos podem ser de matérias-primas necessárias à produção até alguns tipos de conhecimentos, sejam eles tecnológicos, de know-how ou operacionais. $\mathrm{O}$ acesso a um determinado mercado também pode ser considerado um recurso valioso, assim como determinados tipos de informações, entre diversos outros tipos de recursos existentes que poderiam despertar o interesse por um arranjo cooperativo.

Nesse sentido, as alianças são formadas por diferentes razões. Por exemplo, para adquirir conhecimento tecnológico, já que é consenso que nivelar-se a outras organizações quanto a esse tipo de recurso é um fator cada vez mais importante para a sobrevivência num ambiente extremamente competitivo e dinâmico. Dessa forma, algumas alianças buscam o intercâmbio tecnológico, além da pesquisa e do desenvolvimento em cooperação, dentre outras formas de se conseguir vantagens competitivas através do avanço tecnológico. Segundo Madhock (1997 apud DAS E TENG, 2000), cooperações são instrumentos úteis para o desenvolvimento de conhecimento em áreas de funcionamento crítico onde o incremento de conhecimentos é fundamental, haja vista que, sem a atuação em conjunto, poderá ocorrer a falta ou possíveis limitações no desenvolvimento desses conhecimentos num determinado período de tempo ou a um custo aceitável.

Contractor e Lorange (1988) apontam outra possível vantagem de se formar uma aliança estratégica: as vantagens da quase-integração vertical entre duas ou mais corporações; ou seja, a possibilidade de se estabelecer uma cooperação com outra organização que forneça suprimentos ou serviços necessários a sua cadeia produtiva, sem que seja necessário uma integração vertical completa, com todos os custos que isso acarretaria, mas com um determinado nível de integração e comprometimento onde haja uma certa garantia na obtenção desses recursos, com maior eficiência do que no caso de ter que buscá-los no mercado.

Assim, podemos verificar que a teoria da dependência de recursos consegue explicar em grande parte alguns dos motivos que levam empresas em todo o mundo a formarem alianças estratégicas. Todavia, é preciso ter em mente que essa abordagem teórica consegue explicar esses motivos sob um determinado ponto de vista específico, importante para a compreensão do fenômeno, mas insuficiente. Dentre os aspectos limitantes da teoria da dependência de recursos está a visão puramente objetivista da realidade, que desconsidera a possibilidade de se levar em conta o ambiente como uma construção social. Conseqüentemente, muitas vezes são desconsideradas as pressões cognitivas e normativas na tomada de certas decisões quando da escolha das alternativas para reduzir a dependência de recursos. Ademais, essa perspectiva objetivista pode levar ar uma visão limitada, tendo em vista que apenas determinados recursos são considerados. Nessa medida, é importante a observação de outras abordagens teóricas para uma maior compreensão desses novos tipos de arranjos organizacionais.

\section{A formação de alianças estratégicas vista de uma perspectiva da teoria dos custos de transação}

A teoria dos custos de transação (TCT) se baseia em grande parte no estudo de Williamson (1991), no qual este procura explicar a existência e a operação das organizações, mostrando que mercado e hierarquia são formas al- 
ternativas para que as transações possam ser realizadas, sendo essas duas formas chamadas de "mecanismos de governança" (BARNEY; HESTERELY, 2004). Motta e Vasconcelos (2002, p.390) afirmam que "custos de transação são os custos necessários para negociar, monitorar e controlar as trocas entre as organizações, indivíduos e agentes econômicos".

Williamson (1991) procura mostrar que, no início, as transações eram bastante simplificadas, sendo, portanto, conduzidas com perfeição pelo próprio mercado. Entretanto, com o decorrer do tempo, essas transações foram se tornando cada vez mais complexas e incertas, e fatores como, por exemplo, a confiança, tão usual em mercados mais regionais e pouco integrados, passaram a deixar de existir, quando o volume de transações cresceu em grande escala e as transações passaram a ocorrer num âmbito geográfico cada vez maior. Nesse sentido, a hierarquia surgiu como fator fundamental para regular essas transações mais complexas. A organização, portanto, surgiu para Willamson como uma "resposta aos ambientes incertos" (HALL, 2004) e para superar falhas de mercado. Dessa forma, o mercado seria regulado por variáveis como preços, a competição ou por contratos. No sentido contrário, a hierarquia seria formada através da reunião de "partes para uma transação sob o controle direto de terceiros (tipicamente chamados de 'o chefe').” (BARNEY; HESTERELY, 2004, p.135).

A TCT baseia-se em dois pressupostos básicos em relação aos atores participantes de transações econômicas: que esses atores possuem uma racionalidade limitada e que podem ter comportamentos oportunistas.

Valendo-se da teoria da racionalidade limitada de Simon, a teoria do custo de transação procura demonstrar que os indivíduos e grupos organizacionais têm uma capacidade limitada de processar as informações disponíveis. Herbert Simon define o princípio da racionalidade limitada, afirmando que "a capacidade da mente humana para formular e resolver problemas complexos é muito pequena em comparação com o tamanho dos problemas complexos cuja solução é necessária para um comportamento objetivamente racional no mundo real." (SIMON, 1957 apud WILLIAMSON, 1991, p.25). Dessa forma, parte-se do pressuposto de que os agentes econômicos procuram planejar suas ações de forma a maximizar os resultados provenientes destas. Porém, há uma infinidade de possibilidades diferentes de atuação, sendo impossível para qualquer pessoa ou organização, conseguir analisar cada uma delas para se chegar a melhor possibilidade possível. Portanto, afirma Simon (1947 apud BARNEY; HESTERELY, 1996) que aqueles que estão envolvidos nas transações econômicas são "intencionalmente racionais, mas apenas de forma limitada". Assim, parece claro que sem limites racionais, todas as transações poderiam ser planejadas levando-se em conta todas as variáveis possíveis, o que resultaria numa ação com o melhor resultado plausível. Nesse sentido, contratos poderiam ser firmados prevendo todos os acontecimentos possíveis, o que eliminaria incertezas. Porém, a racionalidade dos agentes de fato se coloca como restrita, sendo portanto, a única certeza, a incerteza em relação ao futuro. Nesse sentido, a organização hierárquica surge como uma possibilidade de redução dessas incertezas. Williamson (1991) coloca de forma explicita seu raciocínio, afirmando que

se, em virtude dessas limitações [da racionalidade], torna-se muito custoso ou impossível identificar as eventualidades futuras e especificar, ex ante, as adequadas adaptações a estas, os contratos de longo prazo podem ser substituídos por uma organização interna. Recorrer a ests último permite que a adaptação à incerteza se torne possível mediante processos administrativos em forma seqüencial. Desse modo, em lugar de tratar de antecipar todas as contingências possiveis desde o princípio, se permite que o futuro ocorra. Assim, a organização interna economiza os atributos de racionalidade limitada de quem toma as decisões em circunstâncias nas quais os preços não são "estatísticas suficientes" e a incerteza é um fator relevante. (WILLIAMSON, 1991, p.25)

O segundo pressuposto básico da teoria dos custos de transação trata da questão do oportunismo. Williamson (1991, p.43) coloca que "o oportunismo amplia a suposição convencional de que os agentes econômicos se guiam por considerações de interesse próprio para dar lugar a um comportamento estratégico". Assim, o autor procura mostrar que os atores econômicos muitas vezes comportam-se de forma oportunista, e distinguir esse comportamento nesses diferentes atores torna-se um custo de transação efetivo nas relações comerciais. 
O comportamento oportunista é relevante na medida em que, sem a sua existência, toda transação poderia ser feita na base da promessa (BARNEY; HESTERELY, 2004). Nesse sentido, torna-se importante que determinadas transações fiquem sob a supervisão de uma organização hierárquica, pois isso reduziria o oportunismo, visto que esse tipo de formato organizacional permite o monitoramento do comportamento dos agentes através da supervisão direta, da auditoria e de outros mecanismos de controle. (HALL, 2004)

Cabe aos agentes econômicos a escolha da estrutura de mercado mais eficiente (mercado ou hierarquia), devendo essa escolhe levar em conta a minimização dos problemas transacionais gerados pela racionalidade limitada e pelo comportamento oportunista. Desse modo, deve-se ter em mente, antes de tudo, o nível de racionalidade limitada existente numa transação. Quanto maior, maior será a incerteza, e portanto maior será a propensão a se utilizar de uma forma hierárquica de poder. De forma análoga, quanto maior a possibilidade de oportunismo numa dada transação, maior será a propensão a se implementar uma forma hierárquica de poder. Child e Faulkner (1998) procuram demonstrar como a escolha entre a forma de mercado ou hierárquica deve ser feita, afirmando que quando se trata de transações não recorrentes, de curta duração ou onde não se utilizam ativos específicos, transações baseadas no mercado são consideradas mais convenientes. Todavia, em transações recorrentes, que exigem um tempo maior para amadurecer ou onde se utilizam ativos específicos, uma hierarquia passa a ser mais apropriada.

A teoria dos custos de transação reconheceu, posteriormente, a possibilidade de uma terceira alternativa de organização das atividades econômicas. Seria uma forma híbrida, intermediária entre o mercado e a hierárquica, formato que, na prática, seria caracterizado pelas alianças estratégicas, tais como contratos de longo prazo entre organizações, joint ventures, franquias e rede de empresas, dentre outras. Nesse sentido, Williamson (1991 apud BARNEY; HESTERELY, 2004) afirma que esse formato organizacional seria mais flexível e com uma maior capacidade de adaptação às circunstâncias do que as hierarquias, possibilitando, por outro lado, um maior controle administrativo do que o mercado. Somado a isso, essa estrutura alternativa geraria menos incertezas causadas por falhas de mercado sem a necessidade de se arcar com os altos custos do estabelecimento de uma hierarquia. Dessa forma, alianças fariam sentido quando os custos de transação não fossem tão altos a ponto de ser necessário um controle hierárquico, mas que não fossem tão baixos a ponto de permitirem transações intermediadas unicamente pelo mercado (GULATI; NOHRIA; ZAHEER, 2000b).

Segundo Child e Faulkner (1998), a TCT contribuiu para a compreensão da atuação e da formação das alianças, no tocante à relevância dos motivos dos parceiros, à natureza dos investimentos e ao caráter específico das transações. Além disso, afirmam que a teoria esclarece o critério da eficiência, que demonstra que uma companhia irá preferir formar uma aliança a seguir outra estratégia apenas quando os custos de transação envolvidos nessa aliança forem menores que os de outras opções. Assim, fica claro que a formação de uma aliança estratégica não será sempre a melhor alternativa para uma empresa, pois, apesar de reduzir alguns custos de transação, também pode gerar outros custos antes inexistentes, como a necessidade de se monitorar o parceiro para evitar comportamentos oportunistas. O que parece fundamental, portanto, é conseguir se chegar à estratégia mais viável levando em conta esses custos.

\section{Considerações finais}

Esse artigo objetivou mostrar como as teorias da dependência de recursos e dos custos de transação conseguem explicar, sob determinados pontos de vista, a formação de alianças estratégicas.

A teoria da dependência de recursos procura demonstrar que é de grande valia para as organizações procurar estabelecer relações de cooperação com o intuito de facilitar seu acesso a determinados recursos escassos, sem os quais elas não poderiam sobreviver. Nesse sentido, esses arranjos parecem surgir como uma possibilidade para empresas que possuem recursos complementares, visando ganhos competitivos. Já a teoria dos custos de transação procura evidenciar como a formação dessas alianças pode reduzir os custos de transação para as organizações formadoras desses arranjos. 
É interessante ter em vista, contudo, que essas teorias podem se cruzar ao explicar o fenômeno da formação de alianças estratégicas, já que, por exemplo, quando ocorre a formação desses arranjos, visando a um maior acesso a determinados recursos, isso gerará, em contrapartida, uma redução nos custos de transação, pois serão reduzidos os custos operacionais que seriam necessários para se buscar esse determinado recurso no mercado.

Hennart (1991) faz uma associação entre a abordagem das duas teorias, mostrando que a formação de uma joint venture será efetivada quando os parceiros precisam de bens complementares cuja compra teria um alto custo de transação pelas vias de mercado, e cuja aquisição seria igualmente custosa por intermédio de fusão ou aquisição da outra companhia.

No mesmo sentido, Jones e Hill (1988 apud MOTTA e VASCONCELOS, 2002, p.391) fazem uma associação entra as duas teorias de forma precisa, afirmando que:

Associando os princípios de teoria da dependência de recursos e da teoria dos custos de transação, pode-se dizer que quanto maior for a dependência que uma organização tem dos recursos fornecidos pela outra (por exemplo, que um cliente tem de um fornecedor), maior será o tipo de controle que essa organização procurará exercer sobre a outra, a fim de reduzir a incerteza da dependência. Por sua vez, quanto maior for o nivel de controle que uma organização tentar exercer sobre a outra para reduzir a incerteza, maior serão os custos de transação envolvidos nessa operação. (JONES e HILL, 1988 apud MOTTA e VASCONCELOS, 2002, p.391)

É importante frisar que ambas as teorias explicam de forma complementar os motivos que têm levado as corporações em todo mundo a agirem de forma cooperativa. Contudo, essas duas abordagens teóricas, apesar de bastante relevantes, não são suficientes para a compreensão plena desse fenômeno. É necessário ter em vista que outros fatores que estão além desses discutidos por essas abordagens, são importantes na explicação desses arranjos. A teoria institucional e a teoria da imersão social, por exemplo, explicam de formas alternativas a formação de alianças estratégicas.

Dessa forma, parece inegável que, dada a natureza multifacetada desse fenômeno organizacional, a compreensão da sua complexidade pressupõe a construção de arcabouços teóricos que articulem elementos políticos, culturais, sociais e econômicos. No entanto, é inegável a contribuição das abordagens da dependência de recursos e dos custos de transação, no sentido de esclarecerem os motivos que levam as empresas a cooperarem entre si. 


\section{Referências}

BARNEY, J. B.; HESTERLY, W. Economia das organizações: entendendo a relação entre as organizações e a análise econômica. In: CLEGG, S; HARDY, C.; NORD, W. (Ed.). Handbook de Estudos Organizacionais. São Paulo: Atlas, 2004. v. III, p.131-179.

CHILD, J; FAULKNER, D. Strategies of cooperation: managing alliances, networks and joint ventures. Oxford: Oxford University Press, 1998. p.17-44 e p.65-81.

CONTRACTOR, F.; LORANGE, P. Why should firms cooperate? The strategy and economics basis for cooperative ventures. In:

(Ed.). Cooperative strategies in international business. Lexington, MA: Lexington Books, 1988. p.3-28.

DAS, T. K.; TENG, B-S. A resource-based theory of strategic alliances. Journal of Management, v.26, n.1, p.31-61, 2000.

GLAISTER, K. W.; BUCKLEY, P. J. Strategic motives for international alliance formation. Journal of Management Studies, v.33, p.301-332, 1996.

GULATI, R.; NOHRIA, N.; ZAHEER, A. Guest editors' introduction to the special issue: strategic network. Strategic Management Journal, Hoboken, NJ, v.21, p.199-201, 2000a.

A. Strategic network. Strategic Management Journal, Hoboken, NJ, v.21, p.203-215, 2000 b.

HALL, R. H. Organizações: estruturas, processos e resultados. 8. ed. São Paulo: Prentice Hall do Brasil, 2004. p.250-254 e p.257-259.

HENNART, J-F. The transaction cost theory of joint ventures: an empirical study of Japanese subsidiaries in the United States. Management Science, Illinois, v.37, p.483-487, 1991.

IRELAND, R. D.; HIT, M. A.; VAIDYANATH, D. Alliance management as a source of competitive advantage. Journal of Management, v.28, n.3, p. 413-446, 2002.

MOTTA, F. C. P.; VASCONCELOS, I. F. G. Teoria geral da administração. São Paulo: Pioneira, 2002. p.386-392.

PFEFFER, J.; SALANCIK, G. R. The external control of organizations. New York: Harper \&t Row, 1978.

RODRIGUES, S. B. Formação de alianças estratégicas em paises emergentes: o caso Brasil-China. In: (Org.). Competitividade, alianças e gerência internacional. São Paulo: Atlas. 1999. p.183-190.

WILLIAMSON, O. E. Mercados y jerarquias: su análisis y sus implicaciones antitrust. Fundo de Cultura do México, 1991. 